(c) Elsevier/INRA

\title{
Revised guidelines for gene nomenclature in ruminants 1993
}

COGNOSAG ad hoc committee ${ }^{1,2,3}$

(Received 6 August 1994; accepted 19 October 1994)

\begin{abstract}
Summary - The earlier guidelines proposed by COGNOSAG have been revised to accommodate all ruminants, gene mapping and cloned loci, and to facilitate the development of a genome nomenclature consistent as far as possible with other species.
\end{abstract}

cattle / sheep / goat / gene nomenclature

Résumé - Règles de nomenclature des gènes des ruminants 1993. Il s'agit d'une mise à jour des précédentes directives du COGNOSAG pour la nomenclature génique des ruminants. On s'est efforcé de les rendre applicables à tous les gènes cartographiés et clonés et de faciliter le développement d'une nomenclature interspécifique homogène.

bovin / ovin / caprin / nomenclature génique

\section{INTRODUCTION}

The guidelines from the 1993 Workshop, held at the Turretfield Research Centre, Rosedale, South Australia, are based on earlier proposals from COGNOSAG Workshops at Gontard/Manosque France, July 1986 and July 1987 (Lauvergne and Searle; 1988; Alexieva et al, 1989), Gontard/Manosque, July 1988, and Eugene/Oregon, June 1989 (Alexieva et al, 1990) and Gontard/Manosque, July 1991 (Andresen et al, 1991).

1 Guidelines revised during the COGNOSAG Workshop in October 1993 by E Andresen, TE Broad, S Brown, DW Cooper, L Di Stasio, CHS Dolling, M Fleet, DF Hill, JJ Lauvergne, RS Lundie, J Maddox, FW Nicholas, AL Rae, C Renieri, DP Sponenberg and EM Tucker.

2 Correspondence: JJ Lauvergne, Secretary of COGNOSAG, CRJ/INRA, 78352 Jouy-enJosas cedex, France; or CHS Dolling, President of COGNOSAG, Box 74, McLaren Vale, SA 5171, Australia.

${ }^{3}$ Dedicated to the memory of Bent Larsen, member of the COGNOSAG, died 1992. 
The core of these revised guidelines consists of the 1991 proposals (Andresen et $a l, 1991)$. Their re-wording has been undertaken to reduce their length, and to increase their clarity. The earlier recommendations to limit the length of symbols of loci and alleles to a maximum of 5 and 4 characters, respectively, has been relaxed. The designation of top dominant and codominant alleles by a capital initial letter has been undertaken to assist in the recognition of alleles with visible effects. Thus, the changes made are intended to render the guidelines more permissive and user-friendly, while retaining consistency with the human and mouse systems of nomenclature. Our new recommendations include the use of species prefixes, for example, $O O V$ for sheep, $B B O$ for cattle, and the adoption of the nomenclature for keratins and keratin-associated proteins recently proposed by Powell and Rogers (1993). An additional proposal for provisionally assigning symbols and listing newly reported DNA segments and proteins that have no known homologues, official names or symbols is also outlined.

COGNOSAG will respect as far as possible the names of loci and alleles proposed by authors, and COGNOSAG will propose new names only in the light of new knowledge and consistency with the existing nomenclature.

The use of names and symbols in italics for loci and their alleles is preferred. However, if it is not possible to comply with this, then those names and symbols should be underlined. Authors are asked to be consistent in the underlining or use of italics for the names and symbols within a document and/or file. Locus and allele symbols need not be in italics or underlined in databases, but should be in italics in hardcopy from these databases.

\section{LOCUS}

\section{Locus name}

\section{Choice of name}

The name in English should be as brief as possible but not consist of a single letter, and should convey as accurately as possible the character affected or the function by which the locus is recognised. The name may indicate a morphological (Ear Length) or disease character (Photosensitivity), a body system or body function (Fecundity Java), or a biochemical property (Albumin) or nucleotide segment (DNA Segment: probe $M A F 4$ ).

As far as possible the locus name should reflect interspecies homology.

All Greek symbols should be replaced by roman type and placed after the name, eg, $\beta$ Haemoglobin becomes Haemoglobin beta.

If a newly described locus has an effect similar to one that has already been named, then it may be named according to the breed, geographic location, or population of origin.

\section{Printing the name}

The locus name should be in roman type or a combination of roman type and arabic numerals. Wherever possible, the locus name should be printed in italics, or otherwise be underlined. 
The initial letter of the locus name should be a capital roman character.

If the locus name is 2 or more words, each word after the first word may begin with a capital or lower case roman character, eg, Ear Length, Haemoglobin beta; Ear Length, Haemoglobin beta.

\section{Locus symbol}

\section{Choice of symbol}

For newly reported loci, special care should be exercised in selecting an appropriate symbol to avoid duplication and confusion with existing nomenclature (see Introduction). Every effort should be made to ensure that the symbols selected conform to those in current use for homologous loci.

The locus symbol should consist of as few roman letters as possible, or a combination of roman letters and arabic numerals.

The initial character should always be a capital roman character which, if possible, should be the initial letter of the name of the locus.

For loci other than those for coat colour and visible traits, upper-case roman letters only, or upper-case letters combined with arabic numerals, should be used.

If the locus name is 2 or more words, and the initial letters are used in the locus symbol, then these letters should be in roman capitals.

All characters in a locus symbol should be written on the same line; no superscripts or subscripts, and no Roman numerals or Greek letters should be used.

Where appropriate, the symbol should indicate the biochemical property or designate a particular nucleotide segment.

The rules of mammalian interspecific homology already used in the choice of the name of the locus should be applied to the choice of the symbol.

The designation of prefixes denoting mammalian species of origin should follow that adopted by the Human Genome Nomenclature Committee, when being used to distinguish between the species homologues of a locus (eg, OOV ALB and HSA $A L B)$.

For unmapped DNA segments and proteins that have no known homologues or official names or symbols the first character of the symbol should be $\backslash$ (back-slash) followed by the letters and/or numbers designated by the authors (eg, $\backslash F C B 11$ for the dinucleotide repeat polymorphism at the FCB11 locus, Crawford and Buchanan, Genbank accession No LO1531).

For the keratins and keratin-associated proteins, COGNOSAG recommends that authors adopt the symbols and names proposed by Powell and Rogers (1993).

\section{Printing the symbol}

Wherever possible the locus symbol should be in italics; otherwise it should be underlined, eg, the symbol of the Agouti locus: $A$ or $\underline{\mathrm{A}}$. 


\section{ALLELES}

\section{Allele name}

\section{Choice of name}

The name should be as brief as possible, but should convey the variation associated with the allele. If not given names, alleles should be given symbols as described in the Allele symbol section below.

If a new allele is similar to one that is already named, it should be named according to the breed, geographic location or population of origin. The names of new alleles at a recognised locus should conform to nomenclature established for that locus.

\section{Printing of name}

Wherever possible, the allele name should be in italics; otherwise it should be underlined. A lower-case initial letter of the allele name is preferred. This does not apply when a symbol is used instead of an allele name. For example, the allele for polled condition at the Horns locus in sheep: polled or polled; an allele at the Haemoglobin beta locus: $B$ or $\underline{\mathrm{B}}$.

\section{Allele symbol}

\section{Choice of symbol}

The allele symbol should be as brief as possible, consisting of roman letters and/or arabic numerals.

As far as possible, the allele symbol should be an abbreviation of the allele name, and should start with the same letter. In the loci detected by biochemical, serological or nucleotide methods, the allele name and symbol may be identical.

Greek letters and Roman numerals should not be used.

The symbol + can be used alone for identification of the standard allele ('wild type') for alleles having visible effects. Neither + nor - symbols should be used in alleles detected by biochemical, serological or nucleotide methods. Null alleles should be designated by the number zero.

The initial letter of the symbol of the top dominant allele should be in capitals. When there are only codominant alleles, they should all have a capital initial letter. The initial letter of all other alleles should be lower case.

\section{Printing the symbol}

The allele symbol should always be written with the locus symbol. It may be written as a superscript following the locus symbol, or following an asterisk on the same line as the locus symbol. The allele symbol should be printed immediately adjacent to the locus symbol, ie with no gaps.

Wherever possible, the allele symbol should be in italics; otherwise it should be underlined. 
For example, the recessive allele hornless at the Horns locus in sheep will be printed in italics: $H o^{h 1}$ or $H o^{*} h 1$, or underlined, $\underline{\mathrm{Ho}}^{h 1}$ or $\underline{\mathrm{Ho} * \mathrm{h1}}$. The dominant, allele polled will have the symbol in italics, $H o^{P}$ or $H o * P$; or underlined, $\underline{\mathrm{Ho}}^{\mathrm{P}}$ or $\underline{\mathrm{Ho}} * \mathrm{P}$.

\section{GENOTYPE TERMINOLOGY}

The genotype of an individual should be shown by printing the relevant locus and allele symbols for the 2 homologous chromosomes concerned, separated by a slash, $e g, H o^{P} / H o^{P}$ or $\underline{\mathrm{Ho}}^{\mathrm{P}} / \underline{\mathrm{Ho}}^{P}$.

Unlinked loci should be separated by semicolons.

Linked or syntenic loci should be separated by a space and listed in alphabetical order when gene order and/or phase are not known.

For X-linked loci, the hemizygous case should be designated by / Y following the locus and allele symbol, eg, $F e c X^{*} I / Y$.

$\mathrm{Y}$-linked loci should be designated by / $\mathrm{X}$ following the locus and allele symbol.

\section{PHENOTYPE TERMINOLOGY}

The phenotype symbol should be in the same characters as genotype and allele symbols. The difference is that the characters should not be underlined or in italics and should be written with a space between locus characters and allele characters instead of an asterisk. Square brackets [] may also be used. For example, the dominant genotype $\mathrm{Ho}^{P} / \mathrm{Ho}^{+}$is equivalent to the phenotype $\mathrm{Ho} \mathrm{P}$ or $\left[\mathrm{Ho}^{\mathrm{P}}\right]$.

\section{REFERENCES}

Alexieva SA, Denis B, Dolling CHS et al (1989) Gene nomenclature in sheep and goats 1987. In: Standardised Genetic Nomenclature for Sheep and Goats 1987. COGNOSAG Workshop 1987 (JJ Lauvergne, ed) Bureau des Ressources Génétiques, Paris, France, $17-21$

Alexieva SA, Aliev GA, Bourzat D et al (1990) Gene nomenclature in sheep and goats 1989. In: Loci for Coat Colour of Sheep and Goats 1989. COGNOSAG Workshops 1988 and 1989 (JJ Lauvergne, ed), COGOVICA/COGNOSAG, Clamart, France, 3-7

Andresen E, Broad T, Di Stasio L et al (1991) Guidelines for gene nomenclature in ruminants 1991. Genet Sel Evol 23, 461-466

Lauvergne JJ, Searle AG (1988) Proposed rules for genic nomenclature in sheep and goats. In: Standardised Genetic Nomenclature for Sheep and Goats 1986. COGNOSAG Workshop 1986 (JJ Lauvergne, ed) Bureau des Ressources Génétiques, Paris, France, 107-110

Powell BC, Rogers GE (1993) Differentiation in hard keratin tissues, hair and related structures. In: Keratinocyte Handbook (I Leigh, F Watt, EB Lane, eds). Cambridge University Press, Cambridge, UK (in press) 